\title{
Laboratório de transplante celular: novo cenário de atuação do enfermeiro
}

\author{
Cellular transplantation laboratory: a new field of action for nurses
}

Laboratorio de trasplante celular: nuevo escenario de la actuación de la enfermera

\author{
Maria Inês Corradi', Sandra Honorato da Silva" \\ 'Pontifícia Universitária Católica do Paraná, Laboratório de Engenharia e Transplante Celular. Curitiba, PR \\ "Pontifícia Universitária Católica do Paraná, Curso de Enfermagem. Curitiba PR
}

Submissão: 20/06/2007

Aprovação: 24/11/2007

\section{RESUMO}

O trabalho apresenta um relato de experiência sobre a atuação do enfermeiro num laboratório de transplante celular. Este Laboratório tem por objetivos realizar isolamentos de células produtoras de insulina para transplante em humanos. O enfermeiro como membro da equipe interdisciplinar participa da estruturação da área física, do delineamento dos processos de trabalho, da elaboração de protocolos e de programa de capacitação da equipe. As principais atividades realizadas pelo enfermeiro incluem o controle de contaminação, treinamento em serviço e avaliação da Qualidade dos processos de trabalho desenvolvidos pela equipe interdisciplinar. Os resultados têm demonstrando a efetividade do trabalho do enfermeiro neste novo campo.

Descritores: Enfermeiro; Diabetes mellitus; Transplante de Células.

\section{ABSTRACT}

This article presents the experience of a nurse at a cellular transplantation laboratory. This laboratory goal is to isolate insulin producing cells for human transplantation. The nurse, as a member of an interdisciplinary team, took part in the planning of all work processes: working procedures and team training. The main activities under the nurse responsibilities include contamination control, on-the-job training and evaluation of the Quality of the procedures developed by the interdisciplinary team. Results have shown the effectiveness of the nurses' work in this new field.

Descriptors: Nurse; Diabetes mellitus; Cell Transplantation.

\section{RESUMEN}

El presente trabajo trata de un relato de experiencia sobre la actuación del enfermero en un laboratorio de trasplante celular. El objetivo del laboratorio es realizar asilamientos de células productoras de insulina para transplante en seres humanos. El enfermero, como parte del equipo multidisciplinar tuvo participación en la estructura de todos los procesos del trabajo: elaboración de protocolos y programa de capacitación del equipo. Las principales actuaciones del enfermero incluyen el control de contaminación, entreno en el trabajo y la evaluación de la cualidad de las investigaciones hechas por el equipo multidisciplinar. Los resultados han sido favorables, enseñando la efectividad del trabajo del enfermero en esta nueva área.

Descriptores: Enfermera; Diabetes mellitus; Trasplante de Células. 


\section{INTRODUÇÃO}

A evolução tecnológica na saúde tem impulsionado o desenvolvimento de novas modalidades terapêuticas e exigido consequentemente uma ampliação do papel de profissionais da saúde para garantia de uma equipe interdisciplinar tecnicamente preparada para atuar num novo cenário garantindo o sucesso dos procedimentos.

Assim, a doação de órgãos e o transplante celular vêem demandando reflexões e posicionamento da enfermagem em relação ao papel do enfermeiro nestes novos cenários de forma a delinear o âmbito de competência e garantir o espaço do profissional na equipe.

O trabalho apresenta um relato de experiência sobre a atuação do enfermeiro no planejamento, organização e operacionalização das atividades em um laboratório de Isolamento para transplante de células humanas produtoras de insulina.

A reposição da função das células pancreáticas beta, pelo transplante (Tx) de tecido exócrino, como alternativa de tratamento para diabéticos, com complicações provenientes do diabetes tipo $\mathrm{I}^{(1)}$ tem a vantagem potencial de prevenir ou reverter complicações secundárias do diabetes, diferente da terapia exógena com insulina $^{(2)}$.

A Diabetes Mellitus (DM) é atualmente uma doença epidêmica em crescimento em todo o mundo, com estimativas para o ano de 2010 da ordem de 350 milhões de pessoas portadoras de diabetes ${ }^{(3)}$. Em países em desenvolvimento, a incidência de pessoas com diabetes insulino-dependente (DMID) é maior Que 8\%.

Um estudo internacional mostra Que a prevalência de diabetes em países em desenvolvimento como o Brasil é semelhante ao que ocorre em países desenvolvidos, Quando considerada a população urbana na faixa etária de 30-69, atingindo 5 milhões de diabéticos, sendo a metade não diagnosticada. As complicações tardias da diabetes, principalmente as renais e cardiovasculares representam um problema importante para a sociedade ${ }^{(4)}$.

A introdução do Protocolo de Edmonton em 2000 transformou os resultados e conceitos clínicos sobre o Transplante de ilhotas, após a publicação ${ }^{(5)}$ de uma série de sete pacientes consecutivos com diabetes mellitus tipo I, Que se tornaram independentes do uso de insulina. Mesmo sendo um número pequeno de pacientes, estes resultados pioneiros não somente deram esperança e mostraram sua viabilidade, como também criaram uma importante fundamentação científica para o futuro ${ }^{(6)}$.

Considerando-se o impacto da doença em nossa sociedade e o sucesso do tratamento após o protocolo de Edmonton, ocorreu a decisão da Fundação Pró-renal, em parceria com a Secretaria de Ciência e Tecnologia e a Universidade Católica do Paraná para a implantação do programa de Transplante de ilhotas em Curitiba.

Para a elaboração do projeto do laboratório e o treinamento do pessoal técnico para Isolamento de células humanas produtoras de insulina* para transplante, buscou-se apoio e suporte técnico dos centros de referência em Transplante de ilhotas, do grupo da Clinical Islet Laboratory da Universidade de Alberta, Canadá e do grupo Current Good Manufacturing Practices (cGMP) do Diabetes Research Institute (DRI) da Universidade de Miami, Estados Unidos, estabelecendo-se deste então, um acordo de cooperação técnicocientífica entre estes centros e a PUCPR.

\section{DESENVOLVIMENTO}

Em outubro de 2000, o projeto foi apresentado e aprovado pela Universidade Católica do Paraná e Paraná Tecnologia (Gestor do Fundo Paraná para Programas Científicos e Tecnológicos).

Assim, para a criação do laboratório de transplante de células foi constituída uma equipe interdisciplinar, exercendo o enfermeiro o conjunto de atividades representadas esquematicamente na Figura 1.

Em 200 I , iniciou-se a estruturação da área física do Laboratório de Isolamento para transplante de células humanas produtoras de insulina (LIIH) e as áreas de apoio.

Por não existirem normas específicas para instalações, o dimensionamento, e as instalações prediais do $\mathrm{LIIH}$ observou o preconizado nas tabelas ambientais da Unidade funcional 5 -Apoio técnico - Central de Material Esterilizado simplificado, da Unidade funcional 8 -Apoio Logístico - Limpeza e Zeladoria e no capítulo 7 Que trata das instalações prediais ordinárias e especiais da RDC 50 de 21 de fevereiro de 2002. Além disso, para garantia de Qualidade no processo de Isolamento das Ilhotas, a estruturação do LIIH contemplou principalmente o item 15 - Boas Práticas na Produção e Controle de Qualidade, o item 17 - Produtos estéreis da RDC 210 de 04 de agosto de 2003 e as Normas relacionadas à classificação de partículas em suspensão no ar, como: ISO 14644 partes 1 e $2^{(7)}$.

Salienta-se Que num primeiro momento foi concebido o modelo operacional da área, ou seja, delineada toda a dinâmica de funcionamento do serviço para Que em seguida pudesse ser proposta a área física Que efetivamente atendesse ás necessidades objetivadas.

A estrutura física projetada para o $\mathrm{LIIH}$, Que considerando as características e especificidades das atividades realizadas para o processamento das células, deve disponibilizar um conjunto de ambientes Que atuam como área limpa, ou seja, com classificação de acordo com o número de partículas viáveis em cada ambiente. As áreas de Isolamento A e B, sala fria, cultura de Ilhotas, área central são classificadas como ISO $7^{(7)}$. Os vestiários e desparamentação são classificadas como ISO $8^{(7)}$ e as demais áreas como: estoque, expurgo, sala de administração, microscopia, controle de Qualidade não tem classificação, por não atuarem diretamente no processo de produção de células, e sim como áreas de apoio.

Para certificação da área limpa foram realizados, por empresa especializada, testes de contagem eletrônica de partículas (figura 3), de integridade para filtros HEPA / ULPA, de velocidade do fluxo de ar e balanceamento do sistema no insuflamento e na exaustão, do diferencial de pressão dos filtros, de fumaça, de paralelismo, de indução, de recuperação de temperatura e umidade.

Com a finalização da etapa relacionada ao espaço físico do laboratório, iniciou-se a etapa de organização do serviço pela equipe técnica compreendendo: a descrição de protocolos, procedimentos, normas e rotinas. Foram descritas ainda, as atividades realizadas no laboratório, da captação a emissão das Ilhotas para Transplante, incluindo os procedimentos técnicos para o controle de contaminação.

Em seguida, com base nos protocolos foi elaborado o Programa de Treinamento, para toda a equipe interdisciplinar e serviços 


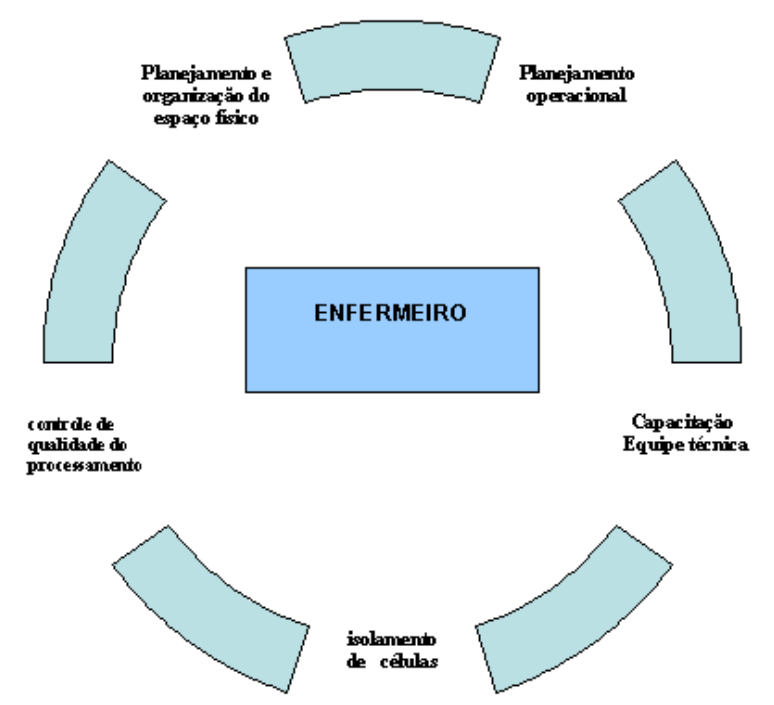

Figura 1. Representação esQuemática das atividades do enfermeiro no Laboratório de Isolamento para transplante de células humanas produtoras de insulina.

terceirizados de forma a garantir um desempenho adequado, convergência e sincronicidade de ações considerando o caráter diferenciado das atividades. Nesse programa foram abordadas as Questões conceituais e operacionais contempladas na atividade, enfatizando-se o controle de contaminação em área limpa, com destaque para higiene pessoal, noções de microbiologia e conduta em áreas limpas, por serem aspectos fundamentais para o sucesso do processo.

Ainda, na etapa de organização foram descritos os indicadores e critérios de avaliação adotados para o Laboratório de Isolamento de Ilhotas: limpeza do laboratório, de materiais, dos equipamentos e dos procedimentos realizados na área limpa.

Para validação do processo de limpeza de superfícies do laboratório foi determinada a avaliação do nível microbiológico pelo método RODAC, Swabs com limites microbiológicos em UFC (unidade formadora de colônia)/placa de contato de 5 e 10 (incluindo piso) para ISO classe 7.

Para os processos de limpeza e esterilização do material foi determinado o uso de água deionizada, embalagem com não tecido e papel grau cirúrgico identificado e realização de testes Químico, físico e biológico, em todos os processos de esterilização e a respectiva documentação.

Todos os equipamentos utilizados no laboratório demandam a descrição do procedimento de calibração, contemplando freeüência e modo de calibração, arQuivo documental dos resultados e manutenção da etioueta dos resultados de calibração, junto ao eQuipamento.

As atividades no laboratório tiveram início em 2002 e desde então foram realizados, apenas 15 isolamentos de ilhotas, em decorrência do baixo número de doações, potencial do doador e propriedades físicas do pâncreas.

O processo de doação de órgãos e tecidos para transplante tem inicio no hospital, Quando da notificação de morte encefálica em um paciente. De acordo a Portaria No 1.752/05 todos os hospitais públicos, privados ou filantrópicos com mais de 80 leitos devem constituir uma Comissão Intra-Hospitalar de Doação de Órgãos e Tecidos.

O enfermeiro como membro desta Comissão pode desenvolver habilidades para atuar no processo de captação de órgãos intervindo na notificação de doador potencial as Centrais de Notificação, Captação e Distribuição de Órgãos (CNNCDO). Segundo a Resolução -COFEN N. ${ }^{\circ} 292^{(8)}$, o enfermeiro deve:

Fornecer a família e representante legal as informações sobre o processo de captação Que inclui: o esclarecimento sobre o diagnóstico da morte encefálica, o anonimato da identidade do doador para a família do receptor e deste para a família do doador; entrevistar o responsável legal do doador, solicitando o consentimento livre e esclarecido por meio de autorização da doação de Órgãos e Tecidos; os exames a serem realizados, a manutenção do corpo do doador em UTI, a transferência e procedimento cirúrgico para a retirada, auxílio funeral e a interrupção em QualQuer fase deste processo por motivo de parada cardíaca, exames sorológicos positivos ou desistência familiar da doação.

Com o diagnóstico da morte encefálica, inicia-se o processo de captação de órgãos, realizada pelo médico cirurgião. Este comunica a Central de Transplante, fornece a família e representante legal as informações sobre o processo de captação, solicitando o consentimento livre e esclarecido por meio de autorização da doação de Órgãos e Tecidos e realiza o procedimento cirúrgico para a retirada do pâncreas. Sendo o órgão (pâncreas) aceito para isolamento de Ilhotas inicia-se o preparo do Laboratório pela equipe técnica. Com o resultado positivo do tecido inicia-se o processo para o transplante no receptor selecionado. As fases do transplante de ilhotas desde a captação, processamento até o transplante das células, conforme o descrito.

Salienta-se Que são estabelecidos critérios de inclusão e exclusão para a doação e utilizados no processo descrito, sendo os mesmos 


\begin{tabular}{|l|l|}
\hline \multicolumn{1}{|c|}{ Critérios de inclusão } & \multicolumn{1}{|c|}{ Critérios de exclusão } \\
\hline Doador de múltiplos órgãos. & Doenças metabólicas pré-existentes. \\
\hline $\begin{array}{l}\text { Tempo de hospitalização inferior a 96 horas } \\
\text { (4 dias). }\end{array}$ & Diagnóstico ou suspeita de septicemia no período do óbito. \\
\hline $\begin{array}{l}\text { Causa do óbito: trauma crânio encefálico, entre outras } \\
\text { condições aceitas pelo grupo de transplante. } \\
\text { Idade do doador entre 25 a } 75 \text { anos. }\end{array}$ & Doenças virais (hepatite, HIV, sífilis), entre outros. \\
\hline
\end{tabular}

\section{Quadro I. Demonstrativo dos critérios de inclusão e exclusão do doador.}

apresentados no Quadro 1.

No período de janeiro de 2002 a abril de 2006 foram realizadas 63 notificações.

Observa-se Que dos 52 órgãos doados apenas 20 foram aceitos para doação, sendo 32 órgãos recusados por estarem fora dos critérios de inclusão apresentados no Quadro 1. Os motivos da recusa foram: sete (7) por não autorização da família; três (3) sem resultado de sorologia; dois (2) sem confirmação de morte encefálica e vinte (20) por outros critérios de exclusão. Dos 20 órgãos doados aceitos apenas 15 estavam em consonância com os critérios.

Assim, 15 pâncreas foram isolados e receberam neste isolamento a seguinte classificação: 2 considerados "ótimo", 7 considerados "bom", 2 considerados "adequado", 2 como "ruim" e 2 como "muito ruim para fins de isolamento", de acordo com as propriedades físicas do pâncreas.

O sistema de pontuação permite uma escolha mais objetiva e consistente, pois determina o potencial do doador aumentando os níveis de sucesso dos isolamentos e diminuindo os custos associados.

Salienta-se que dos 15 isolamentos realizados, apenas I deles resultou em transplante, pelas baixas condições detectadas nos órgãos doados.

Ressalta-se Que todos os procedimentos de isolamento das células, exigem também, testes de hemocultura e gram das células, devendo apresentar resultados negativos como requisito para encaminhamento ao transplante.

As atividades realizadas pela equipe interdisciplinar exigem um rigor de controle de Qualidade de modo a propiciar ao paciente a recepção de células com isenção de riscos decorrentes de contaminação cruzada. Para tanto cabe ao enfermeiro realizar o controle de contaminação, treinamento em serviço e avaliação da Qualidade dos processos de trabalho desenvolvidos pela equipe interdisciplinar.

Para o controle de contaminação o enfermeiro acompanha o processo de limpeza do laboratório, encaminha amostra para testes de avaliação do nível microbiológico das áreas limpas, supervisiona os processos de limpeza e esterilização dos materiais a serem utilizados nos isolamento, realiza o controle dos testes Químico, físico e biológico dos processos de esterilização, bem como a manutenção preventiva e corretiva dos equipamentos.

\section{CONSIDERAÇÕES FINAIS}

O Laboratório de Transplante Celular passa a ser mais um campo de atuação profissional para o enfermeiro envolvendo uma ampla participação no processo de tomada de decisão desde o planejamento e organização do serviço e especialmente no Que tange ao controle de Qualidade do processo.

As atividades realizadas pela equipe interdisciplinar exigem um rigor no controle de Qualidade de modo a propiciar ao paciente a garantia de recepção de células com isenção de riscos advindos de contaminação cruzada.

Até o momento, considera-se Que os protocolos e procedimentos adotados bem como o controle de Qualidade atingem os objetivos de segurança do paciente e da equipe interdisciplinar.

Algumas medidas visando a melhoria no processo de doação e captação de órgãos e tecidos estão sendo projetadas e dentre elas a participação do enfermeiro na organização de programas de conscientização da comunidade, enfatizando a importância da doação de órgãos.

Além disso, um trabalho direcionado aos profissionais de saúde deve ser desenvolvido, enfatizando a obrigatoriedade de notificação à central de transplantes de pacientes com diagnóstico de morte encefálica, a nova tecnologia para o tratamento do diabetes, assim como sobre os resultados desta experiência para incentivar a participação destes profissionais no processo de captação e doação de órgãos.

Espera-se Que com o transplante de ilhotas, maior número de pacientes diabéticos seja beneficiado, diminuindo as complicações da doença e eliminando a insulino-dependência.

Salienta-se Que a resolução COFEN no292/2004(8), incumbe ao enfermeiro aplicar a Sistematização da Assistência de Enfermagem, em todas as fases do processo de doação e transplante de órgãos e tecidos ao receptor e família, Que inclui o acompanhamento pré e pós transplante (no nível ambulatorial) e transplante (intra-hospitalar), sendo o Que se objetiva para a atuação do enfermeiro no LIIH, de forma a monitorar todo o processo e agregar Qualidade á assistência prestada além da incorporação de novos conhecimentos para a enfermagem.

Tem-se a expectativa de Que, com os resultados alcançados, os procedimentos de isolamento de ilhotas, transplante e seguimento pós-transplante tenham um tratamento diferenciado para que o processo seja aperfeiçoado e um maior número de pessoas se beneficie desta tecnologia.

A experiência vivenciada demonstra a importância e viabilidade de se desenvolver um projeto como este, apesar dos obstáculos inerentes aos países em desenvolvimento, desde que todos os profissionais de saúde envolvam-se nesta "luta", e em especial o enfermeiro, realçando ainda, a necessidade deste profissional estar aberto para engajar-se em novas experiências impulsionadas pela evolução tecnológica.

"Um novo cenário de atuação do enfermeiro em prol de saúde e Qualidade de vida da população". 


\section{REFERÊNCIAS}

I. Oberholzer I, Morel P: Perspectives for diabetes treatment through pancreas transplantation or islet transplantation. Diabetes Metab 2002; 28:2S27-22S32.

2. Thomas FT, Hutchings A, Contreras J, Wu J, Jiang XL, Eckhoff $D$, Thomas IM: Islet transplantation in the twenty-first century. Immunol Res 2002; 26: 289-96.

3. 3. Fisher M: Diabetes: can we stop the time bomb. Heart 2003; 89 (supl 2): ii28-30.

4. Matsushima M, LaPorte RE, Maruyama M, Shimizu K, Nishimura $\mathrm{R}$, Tajima N. Geographic variation in mortality among individuals with youth-onset diabetes mellitus across the world. DERI Mortality Study Group. Diabetologia 1997; 40: 21 2-6.
5. Shapiro AM, Lakey IR, Ryan EA, Korbutt GS, Toth E, Warnock GL, Kneteman NM, Rajotte RV: Islet transplantation in seven patients with type I diabetes mellitus using a glucocorticoid-free immunosuppressive regimen. N Engl I Med 2000; 343: 230-8.

6. Shapiro AM, Ryan EA, Lakey IR: Diabetes - islet cell transplantation. Lancet 200 I; 358 (suppl): S2 I .

7. International Organization for Standardization. ISO- I4644I-Claeanrooms and associadted controlled environments. Geneve (SWT): ISO; 1999.

8. Conselho Federal de Enfermagem. Resolução n. ${ }^{\circ}$ 92/2004, Rio de Janeiro (RI): COFEN; 2004. 